\title{
Pentobarbital-induced place aversion learning
}

\author{
GILBERT LEW and LINDA A. PARKER \\ Wilfrid Laurier University, Waterloo, Ontario, Canada
}

\begin{abstract}
Pentobarbital is self-administered by rats but has also been reported to produce a conditioned place aversion. Since the self-administration and place preference paradigms both are considered to assess drug reward, we further examined the hedonic properties of pentobarbital, using place conditioning. In Experiment 1, a dose of $15 \mathrm{mg} / \mathrm{kg}$ (intraperitoneal) of pentobarbital produced a conditioned place aversion after 4 conditioning trials of various durations $(5,15,30$, or $60 \mathrm{~min})$. Since rats are typically drug experienced in the self-administration paradigm, in Experiments 2 and 3, we examined the effect of drug history on pentobarbital-induced place conditioning. Although preexposure to pentobarbital attenuated the place aversion, it never resulted in a place preference. As has been reported with alcohol, pentobarbital is hedonically aversive in rats, when novel.
\end{abstract}

Assessment of the abuse liability of psychoactive drugs commonly employs the paradigms of self-administration (e.g., Weeks, 1962) and place preference learning (see, e.g., Mucha, Bucenieks, O'Shaughnessy, \& van der Kooy, 1982). Generally, the same drugs that animals selfadminister also produce a conditioned place preference (see, e.g., Carr, Fibiger, \& Phillips, 1989; van der Kooy, 1987). This consistency has led investigators to suggest that the two paradigms measure a common feature of drugs (i.e., drug reward). The results of the assessment of the rewarding properties of pentobarbital, however, are not consistent among the paradigms.

Pentobarbital has been reported as producing a conditioned place aversion in a single experiment (Mucha $\&$ Iversen, 1984), yet it is self-administered by animals (Collins, Weeks, Cooper, Good, \& Russell, 1984; DeNoble, Mele, \& Porter, 1984; DeNoble, Svikis, \& Meisch, 1982; Kato, Wakasa, \& Yanagita, 1985; Meisch \& Lemaire, 1989; Vanover, Wenger, \& Woolverton, 1989). Mucha and Iversen (1984) report that, after four chamberpentobarbital pairings at doses of $10-20 \mathrm{mg} / \mathrm{kg}$, subcutaneous (s.c.)--but not of $2.5 \mathrm{or} 5 \mathrm{mg} / \mathrm{kg} \mathrm{s.c.-rats} \mathrm{subse-}$ quently avoided the pentobarbital-paired chamber. In the following experiments, we further examined the hedonic properties of pentobarbital, using the place-conditioning paradigm.

\section{EXPERIMENT 1}

In Experiment 1, we evaluated the role of conditioning trial duration in the establishment of pentobarbital place

This research was supported by a research grant from the Natural Sciences and Engineering Research Council to L.P. (OGP 92057) and constitutes thesis data collected for an M.A. awarded to G.L. It was presented at the 27th annual meeting of the Society for Neuroscience, New Orleans, October, 1997. We thank Marion Corrick for assistance in maintaining the health of the animals. Correspondence concerning this article should be addressed to L. A. Parker, Department of Psychology, Wilfrid Laurier University, Waterloo, ON N2L 3C5, Canada. conditioning. In the single report of pentobarbital place conditioning, Mucha and Iversen (1984) employed a conditioning trial duration of $60 \mathrm{~min}$. More recently, Cunningham and Prather (1992) reported that conditioning trial duration influences the strength of the place conditioning that is produced by the depressant drug ethanol. Specifically, the shorter the conditioning trial duration, the greater the place preference produced by ethanol in mice. Furthermore, it has been reported that a cocaine-induced place preference was produced in rats when the conditioning trial was $15 \mathrm{~min}$ but not when it was $60 \mathrm{~min}$ (Parker, Tomlinson, Horn, \& Erb, 1994). In Experiment 1, we assessed the effect of conditioning trial duration $(5,15,30$, or $60 \mathrm{~min})$ on the strength of the pentobarbital-induced place conditioning that was produced by $15 \mathrm{mg} / \mathrm{kg}$ of pentobarbital.

Furthermore, in an effort to produce a pentobarbitalinduced place preference, Experiment 1 employed intraperitoneal (i.p.) injections of pentobarbital rather than the s.c. injections used by Mucha and Iversen (1984). Pentobarbital has a slower onset of action when administered s.c. than when administered i.p. In humans, the subjectiveliking ratings of barbiturates vary as a function of the speed of onset of the effect of the drug (de Wit, Bodker, \& Ambre, 1991). The factor of speed of onset also affects the strength of a cocaine-induced place preference; when cocaine is administered intravenously (i.v.) it produces a stronger place preference than when administered i.p. (Nomikos \& Spyraki, 1988), and when administered i.p., it produces a stronger place preference than when administered s.c. (Mayer \& Parker, 1993). Therefore, in Experiment 1, the route of administration chosen was i.p., rather than the s.c. route employed by Mucha and Iversen.

\footnotetext{
Method

Subjects. The subjects were 48 Sprague-Dawley rats weighing $250-300 \mathrm{~g}$ on the $1 \mathrm{st}$ day of conditioning. They were housed in pairs in plastic cages and maintained on a 12:12-h light:dark schedule, with all testing being conducted in the light phase. The rats arrived from Charles River Labs (St. Constant, Quebec) I week prior to the conditioning trials, during which they were handled daily. Food and water was available ad lib throughout the experiment.
} 


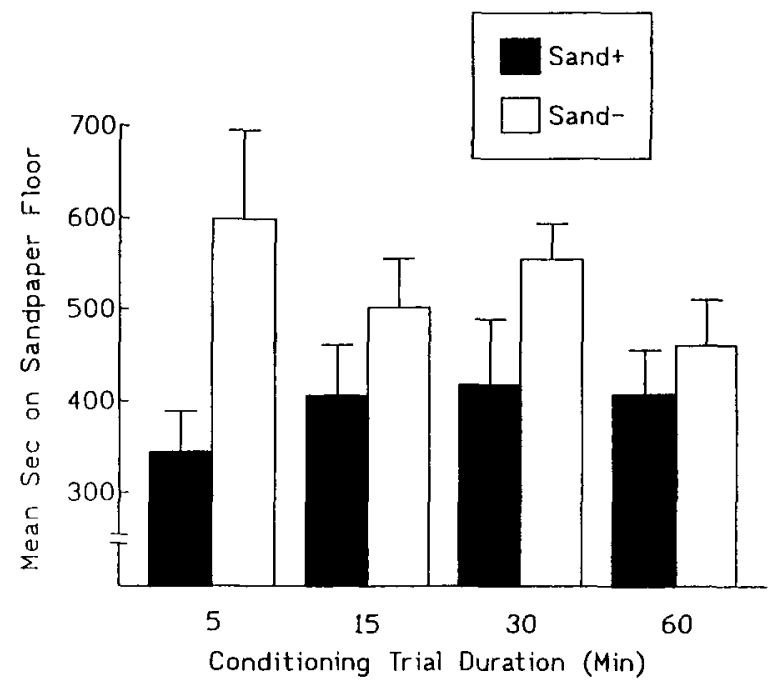

Figure 1. Mean ( $\pm S E M$ ) number of seconds that Groups Sand + and Sand -, conditioned for $5,15,30$, or $60 \mathrm{~min}$, spent in the sandpaper chamber during the 15 -min place preference test of Experiment 1.

Apparatus. The place-conditioning apparatus (described in Erb \& Parker, 1994) included two chambers separated during conditioning trials by a wooden divider. The wooden walls of each chamber $(35 \times 25 \times 30 \mathrm{~cm})$ were painted flat black. The conditioning cues consisted of the textural floors in the chambers: One floor was covered with wire mesh $(0.625 \mathrm{~cm})$, and the other floor was covered with sandpaper strips $(5 \mathrm{~cm})$ located $5 \mathrm{~cm}$ apart. When assessed for their preference for each of these cues after four pairings with i.p.injected saline solution, rats display equivalent preferences for the two floors (Parker, 1996).

During testing, the divider between the chambers was removed, which allowed the rats to explore both chambers. The location of each rat (defined as the widest part of the rat's body) during testing was monitored by a videotracking apparatus (Videomex V; Columbus Instruments). The movement of the white rat against the black background of the chamber was monitored by a videocamera located in the ceiling of the test room. This provided a measure of the amount of time that the rats spent in each chamber.

Procedure. The rats received a total of four differential conditioning trial cycles, as described in Parker (1996). All of the rats were weighed prior to conditioning trial cycles on each day. During each trial, a squad of 8 rats was transported in their home cages into the testing room. On the 1 st conditioning day of a cycle, the rats were injected i.p. with $1 \mathrm{ml} / \mathrm{kg}$ of saline and were returned to their home cage. Five min later (the standard interval in our laboratory's procedure for place conditioning; see, e.g., Parker, 1996), each rat was placed in the chambers with the mesh or sandpaper floor. Twenty-four $h$ later, on the 2 nd conditioning day of a cycle, they were injected i.p. with $15 \mathrm{mg} / \mathrm{kg}$ of pentobarbital $(15 \mathrm{mg} / \mathrm{ml}$ saline $) 5 \mathrm{~min}$ before placement in the opposite chamber to that of the saline trial. The conditioning trial cycles were separated by $48 \mathrm{~h}$. The rats that had the chamber with the sandpaper floor paired with pentobarbital were called Group Sand+ and the rats that had the chamber with the sandpaper floor paired with saline were called Group Sand - . The conditioning trial duration varied among the groups as follows: 5 $(n=12), 15(n=12), 30(n=12)$, or $60(n=12) \mathrm{min}$.

Forty-eight $\mathrm{h}$ after the fourth conditioning trial cycle, the rats were given the place preference test. During the test, the barriers between the chambers were removed, and the rats were allowed to explore the chambers for $15 \mathrm{~min}$ (a commonly employed test duration in place conditioning; see, e.g., Carr, Fibiger, \& Phillips, 1989). The amount of time spent in each chamber was recorded by the videotracking apparatus. Place conditioning was assessed by measuring the mean number of seconds spent in the chamber with the sandpaper floor for the rats that had pentobarbital paired with the sandpaper floor (Group Sand + ) and for the rats that had saline paired with the sandpaper floor (Group Sand-), as previously described by Cunningham, Niehus, and Noble (1993).

\section{Results}

Pentobarbital produced a conditioned place aversion, regardless of conditioning trial duration. Figure 1 presents the mean number of seconds that the rats in Group Sand + and Group Sand - spent in the chamber with the sandpaper floor during the place preference test in Experiment 1 . A $2 \times 4$ between-groups analysis of variance (ANOVA) with the factors of conditioning group (Sand+, Sand -$)$ and conditioning trial duration $(5,15,30$, or $60 \mathrm{~min}$ ) revealed only a significant conditioning group effect $[F(1,40)=10.2, p<.01]$. Rats that had pentobarbital paired with the sandpaper chamber (Group Sand + ) spent less time in the sandpaper chamber than did rats that had saline paired with the sandpaper chamber (Group Sand -$)$. The conditioning trial duration $\times$ conditioning chamber interaction was not significant $[F(3,40)=1.04]$.

\section{Discussion}

As previously reported (Mucha \& Iversen, 1984), pentobarbital produced a conditioned place aversion, and this aversion did not significantly vary on the basis of conditioning trial duration (although the effect appeared to be strongest with the shortest conditioning trial duration). It is unlikely that a lower dose of pentobarbital would produce a place preference, because Mucha and Iversen (1984) reported that $10 \mathrm{mg} / \mathrm{kg}$ was the minimal dose necessary to produce a place aversion and that lower doses of 2.5 and $5 \mathrm{mg} / \mathrm{kg}$ produced neither a place aversion nor a place preference.

The rats were not placed into the conditioning chamber until 5 min after the injection, because this procedure had been commonly employed in other place-conditioning experiments in our laboratory. One might suggest that immediate placement in the conditioning chamber after injection may have produced a place preference rather than a place aversion. However, this result is unlikely, because rats that had the chamber paired with only the early effects of the drug (with a 5 min conditioning trial duration) developed a strong place aversion.

\section{EXPERIMENT 2}

It is consistent with the previous report (Mucha \& Iversen, 1984) that pentobarbital produced a conditioned place aversion. This finding, however, is not consistent with the reported reinforcing properties of pentobarbital, when assessed in the self-administration paradigm. Among the many differences in procedure between placeconditioning and self-administration studies is that of drug history. Generally, animals trained to self-administer 


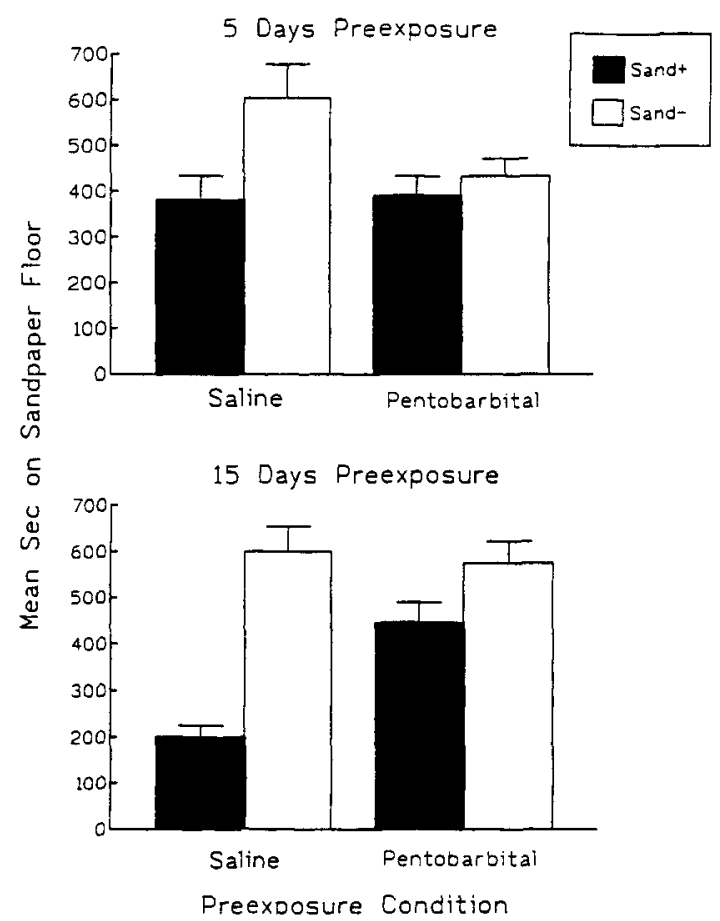

Figure 2. Mean ( $\pm S E M$ ) number of seconds that the rats in Groups Sand+ and Sand - that were preexposed on 5 or 15 days to saline or pentobarbital spent in the sandpaper chamber during the 15-min place preference test of Experiment 2.

pentobarbital are drug experienced, with steady state responding being examined (DeNoble et al., 1984; DeNoble et al., 1982; Kato et al., 1985; Meisch \& Lemaire, 1989; Meisch, Lemaire, \& Cutrell, 1992; Pickens, Muchow, \& DeNoble, 1980; Vanover et al., 1989). On the other hand, most investigations (including Mucha \& Iversen, 1984) of place conditioning employ animals that are drug naive. Drug experience may modify the ability of pentobarbital to produce a conditioned place aversion. In fact, such an effect has been reported with alcohol (Reid, Hunter, Beaman, \& Hubbel, 1985) and nicotine (Shoaib, Stolerman, $\&$ Kumar, 1994). For example, although ethanol produces a place aversion in naive rats, it produces a place preference in ethanol-experienced rats (Gauvin \& Holloway, 1992; Reid et al., 1985).

In Experiment 2, we examined the role of drug experience on the ability of pentobarbital to produce place conditioning. For 5 or 15 days, rats were injected once a day, while in their home cages, with $15 \mathrm{mg} / \mathrm{kg}$ of pentobarbital or with saline. In order to allow for the clearance of any drug build-up caused by daily exposure to this high dose of pentobarbital, 1 week intervened between the end of the preexposure trials and the beginning of the conditioning trials. The ability of pentobarbital to produce place conditioning was subsequently assessed.

\section{Method}

The procedures were similar to those of Experiment 1 . The subjects were 40 experimentally naive Sprague-Dawley rats weighing
$250-300 \mathrm{~g}$ on the 1st day of preexposure injections. During the preexposure phase, the rats were injected i.p. with $15 \mathrm{mg} / \mathrm{kg}$ of pentobarbital $(n=20)$ or with physiological saline $(n=20)$ for each of 5 or 15 consecutive days and were returned to their home cages. One week after the final preexposure trial, the rats received placeconditioning trials in the same manner as in Experiment 1, except that all of the rats remained in the conditioning chamber for $30 \mathrm{~min}$ during conditioning. The test trial was identical to that of Experiment 1.

During the place-conditioning trials, the Videomex system was used to monitor the activity of the group that was given 15 days of preexposure to either pentobarbital or saline. The frequency of crossings (of the widest part of the rat's body) among seven sectors within each chamber was measured during the $30 \mathrm{~min}$ conditioning trial.

\section{Results}

Preexposure to pentobarbital attenuated its ability to produce a conditioned place aversion. Figure 2 presents the mean number of seconds that the rats in Groups Sand+ or Sand - with prior exposure to pentobarbital or saline spent in the chamber with the sandpaper floor during the test trial of Experiment 2. A $2 \times 2 \times 2$ between-groups ANOVA, with the between-groups factors of conditioning group (Sand+, Sand-), preexposure condition (pentobarbital or saline), and number of preexposure days ( 5 or $15)$, revealed a significant effect of conditioning group $[F(1,32)=32.5, p<.01]$ and a significant conditioning group $\times$ preexposure condition interaction $[F(1,32)=$ $10.4, p<.01]$. To evaluate the conditioning group $\times$ preexposure condition interaction (pooled across days of preexposure), subsequent Newman-Keuls pairwise comparison tests revealed that Group Sand+ spent less time in the sandpaper chamber than did Group Sand - among the rats preexposed to saline $(p<.01)$ but not among the rats preexposed to pentobarbital.

Figure 3 presents the mean number of sector crossings per minute during each conditioning trial displayed by rats given 15 days of preexposure to either pentobarbital (pentobarbital experienced) or saline (pentobarbital naive). The dashed line represents the mean number of crossings per minute displayed on the saline treatment days (pooled across the four trials). As is apparent, the rats were less active on the pentobarbital treatment days than on the saline treatment days. On the pentobarbital conditioning trials only, a $2 \times 4$ mixed factor ANOVA of the sector crossings per minute for the factors of pretreatment condition (pentobarbital experienced, pentobarbital naive) and trial (c1-c4) revealed only a significant effect of pretreatment condition $[F(1,22)=8.2, p<.01]$. The pentobarbital-naive rats displayed greater behavioral depression than did the pentobarbital-experienced rats across the conditioning trials, which suggests that the preexposure to pentobarbital produced tolerance to the behavioral suppressant effects of pentobarbital.

\section{Discussion}

Drug experience attenuated the ability of pentobarbital to produce a conditioned place aversion. The mechanism responsible for the attenuation of the conditioned place aversion resulting from drug experience is not clear. It is possible that (1) tolerance developed to the aversive prop- 


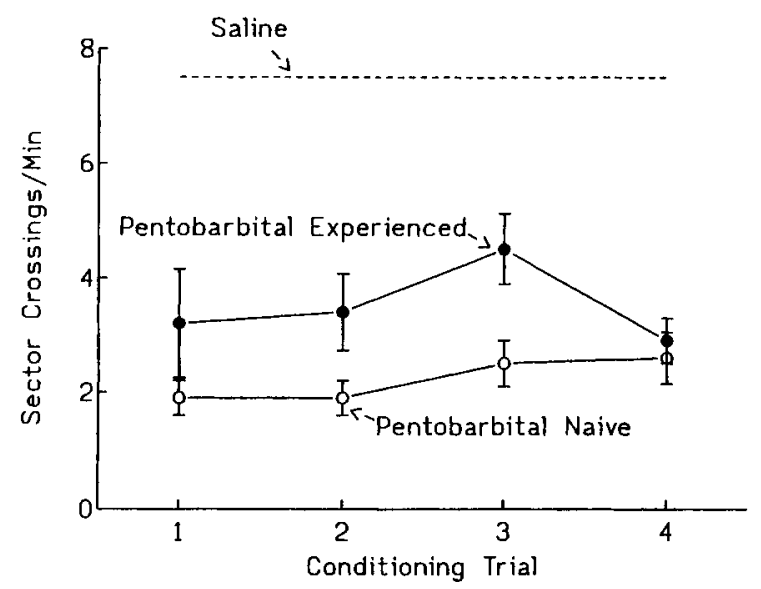

Figure 3. Mean ( $\pm S E M$ ) frequency of sector crossings per minute during conditioning trials for the rats that received 15 days of preexposure to pentobarbital or saline in Experiment 2. Dotted line represents the mean frequency of sector crossings per minute during the saline trials. Solid lines represent the mean frequency of sector crossings during the pentobarbital conditioning trials for the pentobarbital-experienced and for the pentobarbitalnaive rats.

erties of pentobarbital, (2) sensitization developed to the rewarding properties of pentobarbital in combination with its maintained aversive properties, or (3) a nonspecific associative deficit occurred as a result of prior exposure to the conditioning drug in a different context than that of conditioning. However, the third possibility is unlikely, given that preexposure to other drugs in a different context has been shown to increase rather than to decrease the strength of a conditioned place preference (Gauvin \& Holloway, 1992; Lett, 1989; Reid et al., 1985; Shoaib et al., 1994). The dose of pentobarbital clearly produced behavioral suppression during conditioning; however, 15 days of preexposure to the drug reduced (but did not eliminate) its ability to suppress activity.

\section{EXPERIMENT 3}

Although experience with pentobarbital attenuated the place aversion produced by the drug in experimentally naive rats, pentobarbital did not produce a place preference. Yet pentobarbital-experienced rats have been reported to self-administer the drug (DeNoble et al., 1984; Pickens et al., 1980). Even after preexposure, it is possible that the dose of pentobarbital used in Experiment 2 $(15 \mathrm{mg} / \mathrm{kg})$ was too high to produce a preference. Therefore, in Experiment 3, we assessed the effect of place conditioning with low doses of pentobarbital after preexposure to the drug.

Mucha and Iversen (1984) reported that doses of 2.5 and $5 \mathrm{mg} / \mathrm{kg}$ of pentobarbital (which are detectable doses in rats) produced neither a conditioned place preference nor a place aversion. However, there is evidence that the ability of low doses of psychoactive drugs to produce a place preference can be augmented by drug preexposure.
It has been reported that a dose of nicotine $(0.6 \mathrm{mg} / \mathrm{kg}$, i.p.) that was ineffective in producing place conditioning in naive rats effectively established a place preference in nicotine-experienced rats (Shoaib et al., 1994). Beginning $24 \mathrm{~h}$ after the seventh daily injection of nicotine or saline, rats received four nicotine place-conditioning trials. Although nicotine did not produce a place preference in the saline-pretreated group, it did produce a preference in the nicotine-pretreated group. A similar phenomenon has been reported with cocaine following pretreatment exposure with conditioning trials commencing $72 \mathrm{~h}$ after the last pretreatment injection (Shippenberg \& Heidbreder, 1995). Using morphine, Gaiardi et al. (1991) have also reported that daily preexposure injections of $20 \mathrm{mg} / \mathrm{kg}$ of morphine, commencing 12 days prior to the first conditioning session and continuing during conditioning sessions, augmented the ability of $2.5 \mathrm{mg} / \mathrm{kg}$ of morphine to produce a conditioned place preference.

In Experiment 3, we examined the possibility that low doses of pentobarbital $(2.5$ and $5.0 \mathrm{mg} / \mathrm{kg})$ that are reportedly ineffective in producing place conditioning in naive rats (Mucha \& Iversen, 1984) may induce a conditioned place preference in pentobarbital-experienced rats. Rats were preexposed to either $0,2.5$, or $5.0 \mathrm{mg} / \mathrm{kg}$ of pentobarbital for 15 daily sessions prior to conditioning and received 2.5 or $5.0 \mathrm{mg} / \mathrm{kg}$ of pentobarbital paired with a place during the conditioning phase. In a procedure that is more consistent with that used in the previously reported studies that showed augmentation of a preference with drug preexposure, the conditioning trials began $48 \mathrm{~h}$ rather than 1 week after the final preexposure injection.

\section{Method}

The procedures were similar to those of Experiment 1, except as indicated. The subjects consisted of 72 male Sprague-Dawley rats weighing $250-300 \mathrm{~g}$ on the $1 \mathrm{st}$ day of preexposure injections. During the preexposure phase, rats were injected i.p. with $2.5 \mathrm{mg} / \mathrm{kg}$ of pentobarbital $(n=24), 5.0 \mathrm{mg} / \mathrm{kg}$ of pentobarbital $(n=24)$, or physiological saline ( $n=24$ ) on each of 15 consecutive days. Fortyeight $h$ after the final preexposure trial, the rats received placeconditioning trials.

For the conditioning phase, rats in each preexposure condition were divided such that half of the rats in each condition received $2.5 \mathrm{mg} / \mathrm{kg}$ of pentobarbital during conditioning and the other half received $5.0 \mathrm{mg} / \mathrm{kg}$ of pentobaribtal during conditioning. The crossing of three levels of preexposure dose $(0,2.5,5.0 \mathrm{mg} / \mathrm{kg})$ and two levels of conditioning dose $(2.5,5.0 \mathrm{mg} / \mathrm{kg})$ resulted in six conditions $(n=12)$. The rats received place-conditioning ( $30 \mathrm{~min}$ conditioning trial duration) and test trials ( 15 min test trial duration) in a manner that was similar to that of Experiment 2.

\section{Results}

Figure 4 presents the mean number of seconds that the rats in Group Sand + and Group Sand - spent in the sandpaper chamber during the place preference test. Group Sand + represents the rats that had pentobarbital paired with the sandpaper chamber, and Group Sand - represents the rats that had saline paired with the sandpaper chamber. The top half of Figure 4 presents the data for the rats conditioned with $2.5 \mathrm{mg} / \mathrm{kg}$ of pentobarbital, and the bottom half presents the data for the rats conditioned with 


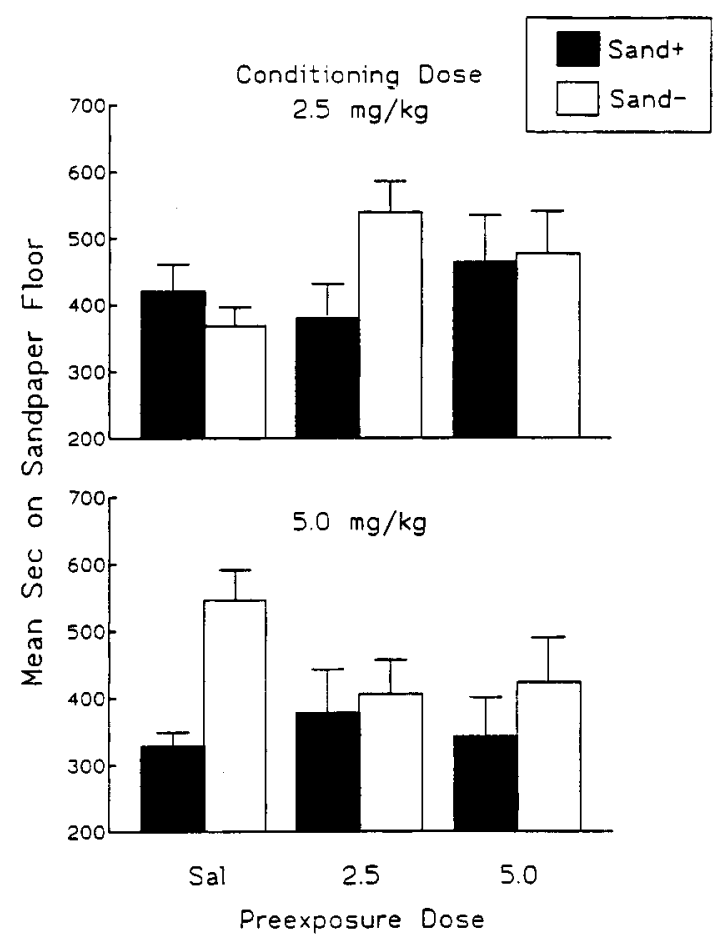

Figure 4. Mean ( $\pm S E M$ ) number of seconds that the rats in Groups Sand+ and Sand - that were preexposed to saline or to 2.5 or $5.0 \mathrm{mg} / \mathrm{kg}$ of pentobarbital and conditioned with 2.5 or $5.0 \mathrm{mg} / \mathrm{kg}$ of pentobarbital spent in the sandpaper chamber during the 15-min place preference test of Experiment 3.

$5.0 \mathrm{mg} / \mathrm{kg}$ of pentobarbital. A $3 \times 2 \times 2$ between-groups ANOVA for the factors of preexposure dose, conditioning dose, and conditioning group revealed a three-way interaction $[F(2,60)=3.6, p<.05]$. To analyze the interaction, separate $2 \times 2$ (conditioning group $\times$ conditioning dose) ANOVAs were conducted for each preexposure condition. These analyses revealed a significant conditioning group $\times$ conditioning dose interaction $[F(1,20)=14.9$, $p<.01]$ for the saline preexposed group only. Subsequent Newman-Keuls pairwise comparisons indicated that the saline-preexposed group conditioned with $5 \mathrm{mg} / \mathrm{kg}$, but not $2.5 \mathrm{mg} / \mathrm{kg}$, of pentobarbital displayed a pentobarbitalinduced place aversion; that is, the rats spent less time in the sandpaper chamber when that chamber was paired with pentobarbital (Group Sand+) than when that chamber was paired with saline (Group Sand $-; p<.01$ ). There were no significant effects for the rats pretreated with either 2.5 or $5.0 \mathrm{mg} / \mathrm{kg}$ of pentobarbital.

\section{Discussion}

The results obtained from the rats conditioned with $5.0 \mathrm{mg} / \mathrm{kg}$ of pentobarbital were in accordance with data gathered from rats conditioned with $15 \mathrm{mg} / \mathrm{kg}$ (see Experiment 2). That is, pentobarbital induced a conditioned place aversion in naive rats but not in rats experienced with the drug. The mechanism responsible for the attenuation of the conditioned place aversion resulting from prior drug experience is unclear. The most plausible explanation of the results at these doses is that pentobarbital was initially aversive but that tolerance developed to the aversive properties of the drug as a result of repeated exposures to the drug. Another explanation is that sensitization developed to the rewarding properties of pentobarbital in combination with its maintained aversive properties. Such a model of sensitization has been used to explain the increase in the strength of place preference produced by amphetamine (Lett, 1989), morphine (Gaiardi et al., 1991; Lett, 1989), cocaine (Lett, 1989; Shippenberg \& Heidbreder, 1995), and nicotine (Shoaib et al., 1994) as rats become more experienced with the drugs.

\section{GENERAL DISCUSSION}

Pentobarbital produced a conditioned place aversion in experimentally naive rats, which replicates the results of Mucha and Iversen (1984). The finding that pentobarbital produced a conditioned place aversion rather than a conditioned place preference raises problems for the assumption that place conditioning and self-administration similarly measure drug hedonics. Monkeys (DeNoble et al., 1982; Meisch \& Lemaire, 1989; Meisch et al., 1992; Vanover et al., 1989) and rats (DeNoble et al., 1984; Pickens et al., 1980) learn to self-administer barbiturates. However, in contrast with the typical place-conditioning procedure, animals trained to self-administer pentobarbital are, generally, drug experienced, and the ability of pentobarbital to maintain steady state responding is assessed.

In Experiments 2 and 3, we examined the role of previous drug history in pentobarbital place conditioning. It can be seen that rats that were pentobarbital-naive at the time of conditioning developed an aversion to a chamber paired with doses of 5 and $15 \mathrm{mg} / \mathrm{kg}$ of pentobarbital. Preexposure to pentobarbital eliminated the place aversion induced by both doses. However, even though prior experience with pentobarbital produced a shift in the hedonics of pentobarbital (as measured by the place-conditioning paradigm) that was in the direction that was predicted on the basis of the performance of drug-experienced animals in self-administration studies, a place preference for pentobarbital was not seen.

The mechanism responsible for the attenuation of the conditioned place aversion resulting from prior drug experience is not clear from our results. It is likely that, at doses of 5-15 mg/kg, pentobarbital was initially aversive but that tolerance developed to the aversive properties of the drug as a result of repeated exposures to the drug. However, it is also possible that sensitization developed to the rewarding properties of pentobarbital in combination with its maintained aversive properties. Such a model of sensitization has been used to explain the increase in the strength of place preference produced by amphetamine (Lett, 1989), morphine (Gaiardi et al., 1991; Lett, 1989), cocaine (Lett, 1989; Shippenberg \& Heidbreder, 1995), and nicotine (Shoaib et al., 1994) as rats become more 
experienced with the drug. An associative mechanism cannot easily explain the attenuation of pentobarbital place aversion with prior drug exposure, because the drug preexposure and drug-conditioning contexts differed.

Self-administration studies employ the i.v. route of administration. Conversely, place-conditioning studies employ methods of drug delivery with a slower onset of action, either s.c. or i.p. This difference in procedure could very well account for the disparate results provided by the two paradigms. It is known that cocaine produces a stronger place preference when administered i.v. than when administered i.p. (Nomikos \& Spyraki, 1988). In a human study in which pentobarbital was orally administered as a single dose or in divided doses such that both methods produced the same peak plasma-drug levels, pentobarbital was found to be more rewarding when administered as a single dose, presumably because the peak was attained more rapidly (de Wit et al., 1991). Therefore, future research should examine the ability of i.v.delivered pentobarbital to produce place conditioning in both drug-experienced and drug-naive rats.

Our manipulation provided no evidence that pentobarbital is rewarding when assessed with the placeconditioning procedure. However, it is conceivable that other manipulations (more preexposure trials, different preexposure injection intervals, different routes of drug administration) might be used that would produce a pentobarbital-induced place preference. This is a matter for further research.

\section{REFERENCES}

Carr, G. D., Fibiger, H. C., \& Phillips, A. G. (1989). Conditioned place preference as a measure of drug reward. In J. M. Liebman \& S. J. Cooper (Eds.), The neuropharmacological basis of reward (pp. 264-319). Oxford: Oxford University Press, Clarendon Press.

Collins, R. J., WeEks, J. R., COOPER, M. M., GoOD, P. I., \& Russell, R. R. (1984). Prediction of abuse liability of drugs using IV selfadministration by rats. Psychopharmacology, 82, 6-13.

Cunningham, C. L., Niehus, J. S., \& Noble, D. (1993). Species difference in sensitivity to ethanol's hedonic effects. Alcohol, 10, 97-102.

Cunningham, C. L., \& Prather, L. K. (1992). Conditioning trial duration affects ethanol-induced conditioned place preference in mice. Animal Learning \& Behavior, 20, 187-194.

DeNoble, V. J., Mele, P. C., \& PorTer, J. H. (1984). Intravenous selfadministration of pentobarbital and ethanol in rats. Pharmacology, Biochemistry \& Behavior, 23, 759-763

DeNoble, V. J., Svikis, D. S., \& Meisch, R. A. (1982). Orally delivered pentobarbital as a reinforcer for rhesus monkeys with concurrent access to water: Effects of concentration, fixed ratio size and liquid positions. Pharmacology, Biochemistry \& Behavior, 16, 113-117.

DE WIT, H., BoDKER, B., \& AMBRE, J. (1991). Rate of increase of plasma drug level influences subjective response in humans. Psychopharmacology, 107, 352-358.

ERB, S., \& PARKer, L. A. (1994). Reactivity to novelty does not predict strength of amphetamine-induced place preference. Pharmacology, Biochemistry \& Behavior, 48, 581-586.

Gaiardi, M., Bartoletti, M., Bacchi, A., Gubellini, C., Costa, M., \& BABBINI, M. (1991). Role of repeated exposure to morphine in de- termining its affective properties: Place and taste conditioning studies in rats. Psychopharmacology, 103, 183-186.

Gauvin, D. V., \& Holloway, F. A. (1992). Historical factors in the development of ETOH conditioned place preference. Alcohol, 9, 1-7.

Kato, S., Wakasa, Y., \& Yanagita, T. (1985). Relationship between minimum reinforcing doses and injection speed in cocaine and pentobarbital self-administration in crab-eating monkeys. Pharmacology, Biochemistry \& Behavior, 28, 407-410.

LETT, B. T. (1989). Repeated exposures intensify rather than diminish the rewarding effects of amphetamine, morphine, and cocaine. Psychopharmacology, 98, 357-362.

MAYER, L. A., \& PARKer, L. A. (1993). Rewarding and aversive properties of IP and SC cocaine: Assessment by place and taste conditioning. Psychopharmacology, 112, 189-194.

MeIsch, R. A., \& Lemaire, G. (1989). Oral self-administration of pentobarbital by rhesus monkeys: Maintenance of behavior by different concurrently available volumes of drug solution. Journal of the Experimental Analysis of Behavior, 52, 111-126.

Meisch, R. A., Lemaire, G., \& Cutrell, E. B. (1992). Oral selfadministration of pentobarbital by rhesus monkeys: Relative reinforcing effects under concurrent signalled differential reinforcement of low rates schedules. Drug \& Alcohol Dependence, 30, 215-225.

Mucha, R. F., Bucenieks, P., O'Shaughnessy, M., \& Van der KoOy, D. (1982). Drug reinforcement studied by the use of place conditioning in the rat. Brain Research, 243, 91-105.

MuCHA, R. F., \& IVERSEN, S. D. (1984). Reinforcing properties of morphine and naloxone revealed by conditioned place preferences: A procedural examination. Psychopharmacology, 82, 241-247.

Nomikos, G. G., \& Spyraki, C. (1988). Cocaine-induced place conditioning: Importance of route of administration and other procedural variables. Psychopharmacology, 94, 119-125.

PARKER, L. A. (1996). LSD produces place preference and flavor avoidance but does not produce flavor aversion in rats. Behavioral Neuroscience, 110, 503-508.

Parker, L. A., Tomlinson, T., Horn, D., \& Erb, S. M. (1994). Relative strength of place conditioning produced by cocaine and morphine assessed in a three-choice paradigm. Learning $\&$ Motivation, 25, 83-94.

Pickens, R., Muchow, D., \& DeNoble, V. (1980). Methohexitalreinforced responding in rats: Effects of fixed ratio size and injection dose. Journal of Pharmacology \& Experimental Therapeutics, 216, 205-209

Reid, L. D., Hunter, G. A., Beaman, C. M., \& Hubbel, C. L. (1985). Toward understanding ethanol's capacity to be reinforcing: A conditioned place preference following injections of ethanol. Pharmacology, Biochemistry \& Behavior, 22, 483-487.

ShipPEnBerg, T. S., \& HeidBreder, C. (1995). Sensitization to the conditioned rewarding effects of cocaine: Pharmacological and temporal characteristics. Journal of Pharmacology \& Experimental Therapeutics, 273, 808-815.

Shoaib, M., Stolerman, I. P., \& Kumar, R. C. (1994). Nicotineinduced place preferences following prior nicotine exposure in rats. Psychopharmacology, 113, 445-452.

VAN DER KOOY, D. (1987). Place conditioning: A simple and effective method for assessing the motivational properties of drugs. In M. Bozarth (Ed.), Methods of assessing the reinforcing properties of abused drugs (pp. 229-240). New York: Springer-Verlag.

VANover, K. E., Wenger, G. R., \& WoOlverton, W. L. (1989). Selfadministration of the isomers of pentobarbital and secobarbital by rhesus monkeys. Pharmacology, Biochemistry \& Behavior, 34, 669-671.

WEEKS, J. R. (1962). Experimental morphine addiction: Method for automatic intravenous injections in unrestrained rats. Science, 138, 143-144.

(Manuscript received August 1, 1997; revision accepted for publication December 10, 1997.) 